See Article page 1933.

\section{Commentary: Re-evaluating minimal volume standards for high-risk cancer resections: Adding socioeconomic determinants of health care delivery to the equation}

\author{
Shawn S. Groth, MD, MS
}

An overarching ideal of health care policy is to optimize health care value, defined as quality divided by cost. ${ }^{1}$ However, the definition of health care quality is complex, multifaceted, and lacks uniform agreement. Consequently, health services researchers have used surrogates of quality, such as hospital ${ }^{2}$ and surgeon procedure volume, ${ }^{3}$ leading both patient advocacy and quality-improvement groups ${ }^{4}$ and major academic hospitals ${ }^{5}$ to advocate for restricting complex operations to hospitals and surgeons who meet certain minimal volume thresholds, such as the "Volume Pledge" endorsed by the Leapfrog Group. ${ }^{4}$ However, many of these thresholds were not established through robust statistical methods, and the volume-outcome relationship for many high-risk cancer operations, including lung cancer resection $^{6}$ and esophagectomy, ${ }^{7}$ are unclear. Nonetheless, these volume standards have significant health care policy implications, as hospitals are increasingly merging into larger health systems and many seek to centralize care.

In this context, Farjah and colleagues ${ }^{6}$ used the Society of Thoracic Surgeons General Thoracic Surgery Database and found no association between perioperative morbidity, mortality, or failure to rescue with hospitals and/or surgeons

\footnotetext{
From the Division of Thoracic Surgery, Michael E. DeBakey Department of Surgery, Baylor College of Medicine, Houston, Tex.

Disclosures: The author reported no conflicts of interest.

The Journal policy requires editors and reviewers to disclose conflicts of interest and to decline handling or reviewing manuscripts for which they may have a conflict of interest. The editors and reviewers of this article have no conflicts of interest.

Received for publication March 13, 2021; revisions received March 13, 2021; accepted for publication March 15, 2021; available ahead of print March 18, 2021. Address for reprints: Shawn S. Groth, MD, MS, Division of Thoracic Surgery, Michael E. DeBakey Department of Surgery, Baylor College of Medicine, 7200 Cambridge St, Suite 6A, Houston, TX 77030 (E-mail: Shawn.Groth@bcm.edu).

J Thorac Cardiovasc Surg 2022;163:1938-9 $0022-5223 / \$ 36.00$

Copyright $₫ 2021$ Published by Elsevier Inc. on behalf of The American Association for Thoracic Surgery

https://doi.org/10.1016/j.jtcvs.2021.03.045
}

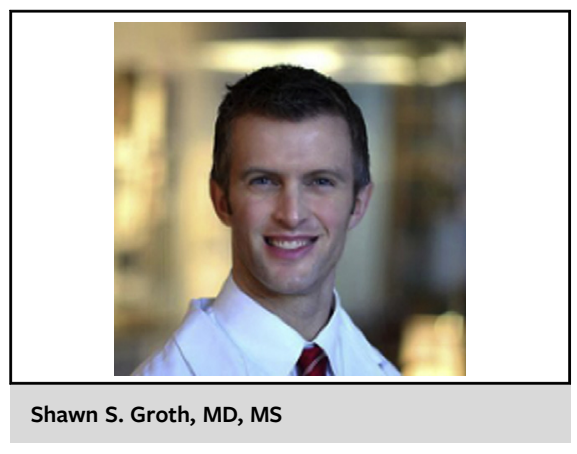

CENTRAL MESSAGE

Rather than hospital and surgeon

volume per se, socioeconomic

determinants of access to quality

health care must be included in

discussions on lung cancer

treatment centralization.

who meet the Volume Pledge threshold for lung cancer resections. The authors suggest that "health system leaders should not centralize lung cancer care on the basis of thresholds specified by the Volume Pledge." ${ }^{6}$ In this issue of the Journal, Sonner and Wakeam ${ }^{8}$ used that study as a launching pad for a broader discussion on the potential impact of social determinants of health care delivery on volumeoutcome relationships and to contextualize the potential value of centralization for certain populations.

Numerous studies have demonstrated disparities in lung cancer care based on race, insurance status, education, place of residence, and income. However, as Sonner and Wakeam point out, the impact of race on lung cancer treatment disparities is less clear when analyses adjust for income, education, insurance status, and neighborhood characteristics, highlighting the importance of controlling for these oftenignored socioeconomic variables when studying health care quality and when assessing the value of health care policy measures such as centralization. While taking into consideration socioeconomic determinants of access to care, further studies are needed to establish volume thresholds through more robust statistical methods and to incorporate more global aspects of cancer care (eg, receipt of adjuvant chemotherapy for node-positive disease, guideline-directed molecular testing, timely surveillance imaging, and 5-year survival rates) into quality assessments, rather than simply perioperative outcomes, which have been the focus in most volume-outcome studies. 
The health care system in the United States does not provide safe, effective, patient-centered, timely, efficient, and equitable care for all its citizens. ${ }^{9}$ If we wish to narrow this health care quality chasm, we need to better understand the complex associations between socioeconomic factors and health care disparities, identify and understand the barriers that impede access to high-quality health care for some, and use that information to prioritize interventions aimed at improving access to and delivery of high-quality care for disadvantaged populations.

\section{References}

1. Porter ME. What is value in health care? N Engl J Med. 2010;363:2477-81.

2. Birkmeyer JD, Siewers AE, Finlayson EV, Stukel TA, Lucas FL, Batista I, et al. Hospital volume and surgical mortality in the United States. $N$ Engl J Med. 2002;346:1128-37.
3. Birkmeyer JD, Stukel TA, Siewers AE, Goodney PP, Wennberg DE, Lucas FL. Surgeon volume and operative mortality in the United States. $N$ Engl J Med. 2003;349:2117-27.

4. The Leapfrog Group. Leapfrog ratings: complex adult surgery. Available at: https://ratings.leapfroggroup.org/measure/hospital/complex-adult-surgery. Accessed March 12, 2021.

5. Urbach DR. Pledging to eliminate low-volume surgery. N Engl J Med. 2015;373: 1388-90.

6. Farjah F, Grau-Sepulveda MV, Gaissert H, Block M, Grogan E, Brown LM, et al. Volume pledge is not associated with better short-term outcomes after lung cancer resection. J Clin Oncol. 2020;38:3518-27.

7. Jacobs RC, Groth S, Farjah F, Wilson MA, Petersen LA, Massarweh NN. Potential impact of "take the volume pledge" on access and outcomes for gastrointestinal cancer surgery. Ann Surg. 2019;270:1079-89.

8. Sonner SN, Wakeam E. The volume-outcome relationship in lung cancer surgery: the impact of the social determinants of health care delivery. J Thorac Cardiovasc Surg. 2022;163:1933-7.

9. Institute of Medicine (US) Committee on Quality of Health Care in America Crossing the Quality Chasm: A New Health System for the 21 st Century. Washington, DC: National Academies Press (US); 2001. 